\title{
The Status Quo and Development Ways of Vocal Music Teaching in Colleges
}

\author{
Li Shan \\ Nanjing Institute of Visual Arts, Nanjing, Jiangsu, 211215
}

\begin{abstract}
Keywords: Vocal Music Teaching in Colleges and Universities; Current Situation; Ways of Development; Teaching Quality; Aesthetic Art
\end{abstract}

\begin{abstract}
With the continuous deepening of education reform in our country, the traditional educational concepts and teaching modes urgently need to be improved and perfected. The teaching content and teaching structure have also been adjusted to some extent. Among them, for vocal teaching in colleges and universities, due to many factors, there are still many defects and shortcomings in practical teaching, which seriously limit the further development of vocal music teaching in colleges and universities, and the actual demand in society is hard to get satisfy. This article mainly analyzes and studies the current situation of vocal music teaching in colleges and universities and further effective ways of developing vocal music teaching in colleges and universities. This provides a reference for colleges and universities to enhance vocal music teaching and improve their vocal teaching level and quality.
\end{abstract}

\section{Introduction}

With the rapid development of social economy, the demand for talents in the market is constantly increasing, which to a large extent directly stimulated the development of Chinese education reform. In order to better adapt to the needs of society, colleges and universities have significantly expanded the number of students enrolled. The number of students majoring in science and technology has greatly increased. At the same time, the number of vocal students has also risen. At the same time, new requirements and challenges have also come up for vocal music teaching in colleges and universities. Vocal teaching is still serious, the traditional concepts of education and teaching mode, it will lead to the overall quality of teaching is not high, and gradually with the world vocal teaching derailed. Therefore, it is necessary to actively take corresponding measures to improve and perfect the current situation of vocal music teaching in colleges and universities in our country, and to improve the teaching level and quality, which is to meet the social and economic development of our country and to promote the long-term development of vocal music teaching.

\section{The Status of College Vocal Teaching}

Since the end of the last century, both the level of arts and culture in our country and the cultural soft power in our country have been continuously improved. The overall development of vocal education in colleges and universities has been effectively developed. However, for the current vocal teaching in colleges and universities in our country, due to many factors Influence, there are still many shortcomings and deficiencies, to a certain extent, limit the improvement of vocal music teaching quality and education development.

Teaching quality will be directly affected by the teaching curriculum, with a certain orientation. At present, the status quo of vocal music teaching in colleges and universities is lack of diversification and diversification. The main teaching courses include piano, harmony, composition analysis, music theory and vocal music skills. However, it is still a big shortage [1]. At the same time, some vocal music teaching in colleges and universities, systematic vocal music theory is also a serious lack of explanation, due to the lack of systematic vocal music theory support, vocal music lessons gradually evolved into a single singing imitation. In addition, for some teachers, the teaching space is large and the teaching method is single, thus it is difficult to guarantee the teaching quality of the vocal music curriculum. The expected teaching goal is naturally difficult to 
be completed. For the students, the imitation can only be simple and the professional knowledge can not be obtained qualitative leap.

Through the comprehensive analysis of the current situation of vocal music teaching in colleges and universities, it can be seen that most of the universities and colleges do not set clear goals for vocal music teaching, which leads to the one-sided pursuit of vocal performance skills in practical teaching and specific training, and to a certain extent, neglected the aesthetic, sentimental and artistic aspects of vocal music teaching, resulting in a weak cultural awareness of students and showing the phenomenon of "light class and heavy class" in ideological concepts. [2] As a result, the goal of vocal music teaching in colleges and universities is rather vague, with some randomness and blindness. On the other hand, it will directly reduce the teaching level and quality of vocal music in colleges and universities, and the overall quality and professional skills of students will be hard to be improved.

It is precisely because of a single curriculum, resulting in many colleges and universities vocal music education there is a big gap between the actual life and the problem. Teaching content will have a significant impact on the quality of teaching, which led to the low level of vocal music teaching and quality. And in some colleges and universities vocal music teaching, did not take into account the students basic knowledge of vocal music and music art training, teaching more students to arrange the songs, and allow students to prepare and direct training and singing. As a result, it is difficult for nature to improve the quality of vocal music teaching. At the same time, students also lack artistic aesthetics and emotion in the process of specific singing. In addition, they can not accurately express singing style and singing style.

Due to the limitations of the traditional concepts, the development of music in the field of education is not perfect enough, and lack of sound rules and regulations, which directly limits the long-term development of music education and music. However, it should be noted that schools are not severely restricted by the relevant education system when formulating their syllabus and rules and regulations. At the same time, it is also necessary to strengthen the outline construction so as to push forward the teaching plan step by step. For the vocal teaching, due to the professionalism, some colleges and universities have some randomness and blindness in the actual teaching process. Because these schools in the development of vocal teaching plan, did not combine the actual social needs, such as the need to innovate what kind of musical traditions, what kind of music people like, social saturation, social needs.

Due to the neglect of vocal education in our country in the first few decades, there is a serious shortage of professionals in our country. As a result, the demands of vocal music teachers in various colleges and universities in our country are not well satisfied. And the comprehensive quality and teaching level of vocal music teachers are uneven, resulting in poor teaching quality and quality, it is difficult to cultivate more high-quality professionals, the vicious circle in the entire vocal teaching [4].

Fundamentally, under the new social environment, the education in our country has been further improved and optimized, and has gradually developed to a new height. As for the vocal teaching in colleges and universities, systematization and specialization have also gradually been highlighted. However, in the process of development, due to the objective existence of various problems, the level and quality of vocal music teaching in colleges and universities is relatively low. Therefore, only by setting reasonable and scientific teaching courses in vocal music teaching in colleges and universities, clarifying teaching objectives and selecting teaching contents according to the actual conditions of students, can we comprehensively improve the overall quality and ability of students and promote the development of highly effective vocal music teaching in our country, For the country to cultivate a large number of high-quality professional vocal talent.

\section{The Effective Way to Further Develop the University Vocal Music Teaching}

In order to ensure that the teaching level and quality of vocal music in colleges and universities can be improved, it is necessary to make effective adjustments to the vocal music curriculum in colleges and universities, and also set "practical comprehensiveness" as the ultimate goal, 
diversification and multi-level setting when setting up teaching courses teaching course First of all, in the course of teaching, the importance of practical courses needs to be highlighted. Teachers can appropriately increase social vocal practice courses and vocal performance performances. Second, you also need to add the theoretical synthesis courses to vocal teaching, such as musical accompaniment courses, vocal music creation courses. Finally, it is necessary to increase the connection between vocal music courses and other related courses, deepen the reform of vocal music teaching and strengthen the expansion in such fields as choral training and computer music production. By setting up a variety of vocal teaching courses, students' interest in learning can be fully stimulated, and students are encouraged to strengthen their own practice and think independently. At the same time, teachers also need to objectively analyze and comment on teaching results so that they can be radically improved vocal music teaching level and quality in colleges and universities.

Teachers as all the teaching activities carried out by organizers, guides, teachers teaching philosophy will directly determine the overall quality of teaching. Therefore, in the teaching of vocal music in colleges and universities, teachers need to actively improve and optimize their own teaching concepts and enhance the overall quality of their professional skills and artistic taste so as to effectively grasp the teaching quality in the actual teaching process. At the same time, in the process of concrete teaching, teachers also need to guide students to gradually understand and analyze vocal works in depth, grasp their cultural connotation from the perspective of arts and culture, ensure that students can get emotional experience, and finally realize the aesthetic needs of vocal art. In addition, in order to carry out teaching activities more smoothly, teachers also need to fully understand and master the basic ability of students and the overall level of development to ensure that they can skillfully apply the artistic characteristics and artistic expression skills related to vocal music teaching in real life and promote the students' cultural and art theories Ability to enhance and guide students to master more vocal music theory and cultural knowledge to ensure that the quality of teaching of vocal music in colleges and universities can be fully enhanced [6].

In the teaching of vocal music in colleges and universities, students should be taught the vocal singing skills as the basic teaching content, meanwhile, students should be guided to further understand the corresponding vocal music works. After knowing the feelings expressed by the songs and the creative background, and then learn and practice songs, which plays an important role in improving the quality of vocal music teaching in colleges and universities [7]. By adjusting the content of vocal music teaching, it can provide the basic guarantee for improving the vocal music teaching quality in colleges and universities, which is also an important content in the reform of vocal music teaching in colleges and universities.

Vocal music art is the art of people can produce emotional resonance, can produce sensory beauty. In the teaching of vocal music in colleges and universities, teachers should pay attention to vocal skills such as singing, pronouncing, breathing and so on, and gradually strengthen their aesthetic awareness of vocal music. This plays an important role in improving students' ability to understand vocal music better. For example, for excellent vocal works, melody and content in them all are real and objective reflections of life, so in order to better express the thoughts and emotions contained in the songs and accurately interpret the reality in the songs Connotation, the singer must understand the content of the song in depth, and effectively integrate the works of emotion, which is also a singer tribute to the song creator attitude. Therefore, in the teaching of vocal music in colleges and universities, teachers need to strengthen the students' understanding of emotion, art and culture of song works better. At the same time, it is also necessary to cultivate the vocal aesthetic ability of students, form the artistic aesthetic ability, fully excavate the cultural precipitation in vocal music works, Gain the beauty of art [8].

In the analysis and research to improve the quality of vocal teaching in colleges and universities, we found that the purpose of improving the quality of vocal music teaching in colleges and universities is to cultivate more high-quality professional vocal talents so as to better meet the needs of the society. For excellent high-quality professional vocal talents, on the one hand, they should be able to master and master basic vocal singing skills and theoretical knowledge. On the other hand, 
they should also adapt themselves to the needs of social development. In actual teaching, they can only rely on the correct teaching objectives Only in this way can we fundamentally improve the teaching level and quality of vocal music in colleges and universities and avoid detours. Therefore, in the teaching of vocal music in colleges and universities, teachers need to strengthen the cultivation of students' vocal artistic sentiments and effectively enlighten their vocal arts wisdom so as to ensure that students can use the professional knowledge they possess to provide services to others in their later work [9]. At the same time, teachers also need to strengthen the improvement and optimization of vocal music teaching methods, pay attention to cultivating students' professional qualities, and the further optimization of teaching structure is of great significance and effect to improve the teaching level and quality of vocal music in colleges and universities. By effectively cultivating and improving students' comprehensive qualities and professional qualities in vocal music teaching at colleges and universities, we can guide students to establish service concept and construct the ultimate goal so as to ensure that the quality of vocal music teaching in colleges and universities can be fundamentally improved.

\section{Conclusion}

In general, due to the particularity of vocal music teaching in colleges and universities, it can not be simply regarded as a teaching course. If we analyze and understand from this perspective, it will definitely affect vocal teaching have a certain dwarf. Therefore, in the process of promoting the development of vocal music teaching in colleges and universities, we must first stand in the field of art, pay attention to the cultivation of students' aesthetic ability and artistic accomplishment, guide students to fully tap and develop the charm of vocal music art, and secondly, realizing that the development of vocal music teaching in colleges and universities can not only improve the artistic aesthetic ability and artistic accomplishment ability of professional students, but also help improve the quality of students in the whole school. Finally, if the conditions permit, colleges and universities should actively build the vocal music teaching and arts center, And the vocal culture as a background, for all sectors of the community to provide vocal music service, which helps to enhance the service capacity of music culture. Only in this way can the teaching quality of vocal music in colleges and universities be improved at the same time, effectively promote the construction of art and culture in our country and promote the better communication and development of arts and culture.

\section{Acknowledgement}

Project: College "Blue Project" outstanding young backbone teachers training object project.

\section{References}

[1] Wei Ran. Discussion on the Necessity and Measures of Cultivating Students' Cross-border Ability in Vocal Music Teaching [J]. The Big Stage, 2012,08: 229-230.

[2] Liu Ximei. Analysis of the status quo and development of vocal music teaching in colleges and universities [J]. Big Stage, 2012,08: 196-197.

[3] Xia Jing. Research on the Status Quo and Reform of College Vocal Music Teaching [J]. Music Times, 2014,03: 184-185.

[4] Zheng Jian. Current Situation and Countermeasures of Vocal Music Teaching in Colleges and Universities [J]. Art Research, 2014,03: 124-125.

[5] Pu Tongwei on how to improve the quality of vocal teaching in colleges and universities [J]. Theater House (first half), 2013,07: 145-146.

[6] Li Li. Reform and innovation of vocal music teaching in colleges and universities [J]. Art and Technology, 2013,2603: 288. (2013-06-03) [2017-09-27]. 
[7] Deng Fali. Misunderstandings and Optimization of Vocal Music Teaching in Colleges and Universities [J]. Sichuan Drama, 2013,08: 156-158. (2013-11-05).

[8] Liu Xin. Discussion on ways to improve the teaching efficiency of vocal music in colleges [J]. The Voice of the Yellow River, 2015,01: 26.

[9] Liu Ting. Analysis of Vocal Music Teaching Reform Based on the Problems in Vocal Music Teaching in Universities [J]. The Voice of the Yellow River, 2016,19: 46. (2017-01-06). 